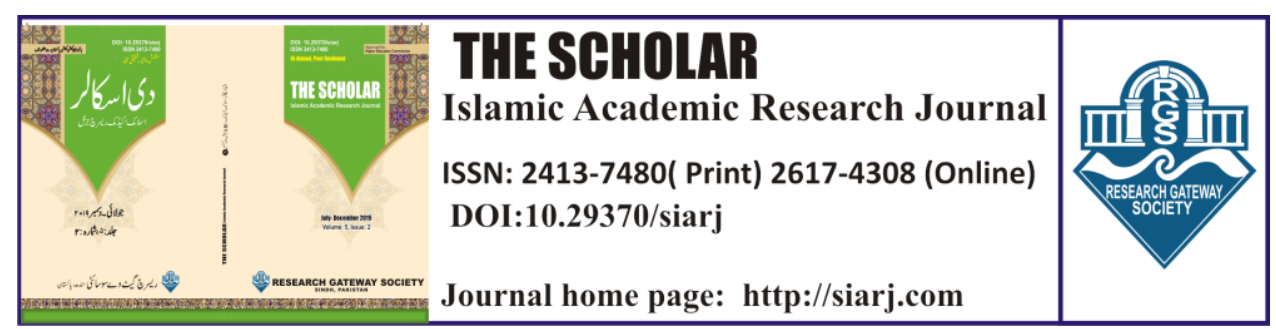

\title{
CORRELATION AMONG RELIGIOUS ORIENTATION, MENTAL HEALTH AND ACADEMIC PERFORMANCE AT HIGHER EDUCATIONAL LEVEL
}

\section{Dr. Asif lqbal}

Assistant Professor of Education, University of Education Faisalabad

Campus, Pakistan

Email: zahidaphd@gmail.com

ORCIID IID:

https://orcid.org/0000-0003-1488-8197
2. Dr. Zahida Javed

Assistant Professor of Education, GC Women University Faisalabad, Pakistan Email: asifphd@gmail.com

ORCIID IID:

https://orcid.org/0000-0001-6836-9507

\section{Dr. Hadi Bux}

Assistant Professor. Mehran University, SZAB Campus Khiarpur Mir's, Sindh, Pakistan. Email: hadibukhsh@gmail.com

ORCIID IID:

https://orcid.org/0000-0002-3390-0975

To cite this article:

Iqbal, Asif, Zahida Javed, and Hadi Bux. "CORRELATION AMONG RELIGIOUS ORIENTATION, MENTAL HEALTH AND ACADEMIC PERFORMANCE AT HIGHER EDUCATIONAL LEVEL." The Scholar-Islamic Academic Research Journal 5, No. 2 (December 16, 2019): 40-54.

To link to this article: https://doi.org/10.29370/siarj/issue9ar9

\begin{tabular}{|c|c|}
\hline Journal & $\begin{array}{l}\text { The Scholar Islamic Academic Research Journal } \\
\text { Vol. 5, No. } 2 \text { || July -December } 2019 \text { || P. 40-54 } \\
\text { Research Gateway Society }\end{array}$ \\
\hline DOI: & 10.29370/siari/issue9ar9 \\
\hline$\overline{\text { URL: }}$ & https://doi.org/10.29370/siarj/issue9ar9 \\
\hline License: & Copyright c 2017 NC-SA 4.0 \\
\hline Journal homepage & www.siarj.com \\
\hline Published online: & $2019-16-12$ \\
\hline
\end{tabular}
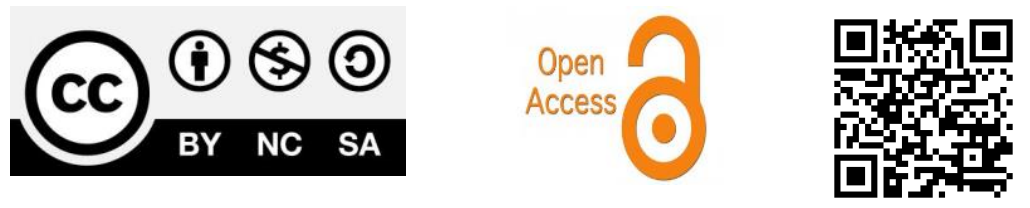
THE SCHOLAR (July - December 2019)

CORRELATION AMONG RELIGIOUS ORIENTATION, MENTAL HEALTH AND ACADEMIC PERFORMANCE AT HIGHER EDUCATIONAL LEVEL

Dr. Asif Iqbal, Zahida Javed, Hadi Bux

\begin{abstract}
:
The association between mental health and religious orientation is most researched field of clinical psychology. Over the years, the researchers and practitioners try their bet to cope the remedies in human life. The current study is an intention to trace factors responsible for performance among university students and to find the correlation between mental health and religious orientation. It was a descriptive study with survey method. Three hundred scholars from different departments of University of Education Faisalabad campus were selected randomly. The questionnaire named, Religious Orientation and Mental Health Survey [ROMHS] was used. The Cronbach Alpha values of intrinsic and extrinsic religious orientations were .861 and .845 respectively as well as mental health .863 . The findings revealed significant and strong relationship among intrinsic and extrinsic religious orientations and mental health. Male students had higher extrinsic religious orientations and mental health than females. It was found that about $81 \%$ of academic achievement score of university students was influenced by religious orientation and mental health. It was and clinical aspects
\end{abstract}

KEYWORDS: Religious Orientation, Mental Health, Academic

Performance

\title{
Introduction
}

The concept of mental health and mental pressure is most prevailing field among many researchers in the field of psychology now a day. The 
remedies to cope with anxiety and stress have common concerns in our daily life. The role of stressful situation is not rare in human life. However, the causes of stressful situations and coping strategies differ from person to person. The proposed remedies and techniques to manage stressful measures play a significant part in mental and physical health. ${ }^{1}$

Depression, anxiety, and stress with coping strategies are parts of our lives. The disasters and failure of human life are major sources of stress. It is the main reason of mental diseases and incompatibilities. From academic point of view, methods used by students to attain stressful causes play significant role in identifying mental and physical health. ${ }^{2}$ Feeling of religious commitment is an effective way parents may cope with shocking news about their kids' blood disarrays. ${ }^{3}$ Most of the researchers identify significant correlation between metal well-being and religious beliefs. ${ }^{4}$

Some researchers investigated that misty and vague correlation between different spirituality and psychological compatibility. It showed

1 Moos, Rudolf H. \& Schaefer, Jeanne A, "Coping resources and processes: Current concepts and measures". In: Goldberger L, Breznitz S, editors. Handbook of stress: Theoretical

${ }^{2}$ Alireza Jafari, "Relationship between religious orientation (InternalExternal) with methods of overcoming stress in students of Islamic Azad University of Abhar". Psychology Research 1 No. 4(2011): 239-243.

${ }^{3}$ Crystal L. Park. \& Lawrence H. Cohen, "Religious and nonreligious coping with the death of friend". Journal of Cognitive Therapy and Research 17 No. 6(1993): 561-577.

${ }^{4}$ Christopher G. Ellison, "Religious involvement and subjective wellbeing”. Journal of Health and Social Behavior 32 No. 1(1991): 80-99. 
that religious beliefs have both positive and negative effect on mental health with respect to personal religious concerns and consequences. ${ }^{5}$

\section{Religious Orientation}

Religious orientation appears to reflect drastically different values and beliefs. Many motives are present for being religious. Psychologists refer religious orientation as a person's practices or lives about religious beliefs. The basic aspects of religious orientation as extrinsic and intrinsic. ${ }^{6}$ Intrinsic religious orientation in person considers religion as master drive in life and an ultimate end product. There are internalized religious beliefs and values to be reorganized, accommodated, and took in harmony with religious context. An intrinsic religious orientation makes the human life motivated and purposeful. It has deep internalized and genuine religious faith.

The extrinsic religious oriented people consider religion as utilitarian and instrumental fashion. They attained self-centered ends like safety and sociability. For them, religion is light, over simplified and less integrated life subject. The extrinsically oriented people treat religion as social status and safety.

\section{Religiosity Orientations and Mental Health}

The current study examines the role of religious orientation under academic stress among students. It is an intention to explore either

\footnotetext{
${ }^{5}$ Alireza Jafari, "Relationship between religious orientation (InternalExternal) with methods of overcoming stress in students of Islamic Azad University of Abhar". Psychology Research 1 No. 4(2011): 239-243

${ }^{6}$ Maria Hovemyr, "The attribution of success and failure as related to different patterns of religious orientation". International Journal for the Psychology of Religion 8 No. 2(1998): 107-124.
} 
students use religion to decrease the levels of academic stress. According to Islamic point of view, religion is the combination of acts, beliefs, and adoration. They are "Iman", "Amal", including "Ibadah". Many diverse circumstances may be better handled under the light and teachings of religion. The managing strategies of religious have positive association with different situations. ${ }^{7}$ The optimistic orientations about religion have a confident and constructive care and benefits to cope for tense life situations. While destructive religious desires lead to frustration. ${ }^{8}$

The religious skills and sources (prayers, religious activities, and reading Quran) are significantly related to the academic stress among students. By using these skills, the students control their academic stressors during their studies in university. ${ }^{9}$ Many studies revealed that students use internal religious orientations for problem solving and external-oriented ones use emotion created coping. ${ }^{10}$ The intrinsic orientation is positively linked with better mental health and determination to cope with guilt and worries. Intrinsic religiosity anticipated low level of

${ }^{7}$ Christian Zwingmann, \& Sebastian Murken, "Coping with an uncertain future: Religiosity and millenarianism". Archives for Religions Psychology 23 (2000): 11-28.

${ }^{8}$ G. G Ano, \& E. B. Vasconcelles, "Religious coping and psychological adjustment to stress: A meta-analysis". Journal of Clinical Psychology 61 (2005). 461-480.

${ }^{9}$ Marwan Zaid Bataineh, "Academic stress among undergraduate students: The case of education faculty at King Saud University”. International Interdisciplinary Journal of Education 2 No. 1(2013): 82-88. ${ }^{10}$ Alireza Jafari, "Relationship between religious orientation (InternalExternal) with methods of overcoming stress in students of Islamic Azad University of Abhar". Psychology Research 1 No. 4(2011): 239-243. 


\section{Correlation among Religious Orientation, Mental Health and Academic Performance at Higher Educational Level}

depression. $^{11}$ There is a significant difference between the external and internal religious orientation in the emotion based coping methods like self-control, confrontation, avoidance and escaping. ${ }^{12}$

\section{Academic Performance and Mental Health}

The complex academic environment has great medical problems for pupils' lives and restricted the gains expected from university studies. ${ }^{13}$ It needed proper coping strategies of stress management in university for effective academic progress. Students in universities have diverse expectations, values and goals needed to fulfill. ${ }^{14}$

In literature, many academic factors that are associated with academic performance are identified like time management, economic burdens, teachers' students' interaction, social activities, academic adjustment, campus life, group work stress, and lack of support from peers. ${ }^{15}$ In addition, admission criteria, high student-teacher ratio, overcrowded class rooms, absence of teacher-student communication,

\footnotetext{
${ }^{11}$ Sam G. McFarland \& James C. Warren, Jr., "Religious orientations and selective exposure among fundamentalist Christians". Journal for the Scientific Study of Religion, 31 No. 2(1992): 169-174.

12 Alireza Jafari, "Relationship between religious orientation (InternalExternal) with methods of overcoming stress in students of Islamic Azad University of Abhar". Psychology Research 1 No. 4(2011): 239-243.

13 Karen Danna, \& Ricky W. Griffin, "Health and well-being in the workplace: A review and synthesis of the literature". Journal of Management 25 No. 3(1999): 357-384.

14 Suhail Bhat, "Religious orientation and academic stress among university students". International Journal of Behavioral Research \& Psychology 3 No. 3(2015): 85-89.

15 Scott, E. Wilks, "Resilience amid academic stress: The moderating impact of social support among social work students". Advances in Social Work 9 No. 2 (2008): 106-125.
} 


\section{Correlation among Religious Orientation, Mental Health and Academic Performance at Higher Educational Level}

corporeal punishment, excessive school-work, teaching methods, and low emphasis on quality rather than quantity. ${ }^{16}$ Expectations from teachers and parents. ${ }^{17}$ The academic workload, class bunking exams, overburdened syllabus $^{18}$, lack of modern technology ${ }^{17}$, unable to use $\mathrm{ICT}^{18}$, low educational performance ${ }^{19}$ (Johnson, 2009), students' strength in classes and absence of academic plans (Conner, et al., 2010), upcoming unemployment feelings ${ }^{18}$, extra requirements, peer interaction, prospects from families ${ }^{17}$, community and teachers ${ }^{18}$, monetary burden ${ }^{19}$, tiresome entrance fee procedures ${ }^{20}$, obstructions, and academic pressure. ${ }^{21}$ After extensive study of literature, theoretical and empirical features of study variables, mental health, religious orientation, and academic performance the current study was carried out among university scholars.

\section{Study Objectives}

The objectives were as under for the study:

${ }^{16}$ Rudolph KD. \& Hammen C, "Age and gender as determinants of stress exposure, generation, and reactions in youngsters: A transactional perspective”. Child Development 70 No. 3(1999): 660-677.

${ }^{17}$ Joseph E. Agolla, \& Henry Ongori, "An assessment of academic stress among undergraduate students: The case of University of Botswana". Educational Research and Review 4 No. 2(2009): 63-70.

${ }^{18}$ Mohsin Shah, Shahid Hasan, Samina Malik, \& Chandrashekhar $T$ Sreeramareddy, Perceived Stress, Sources and Severity of Stress among medical undergraduates in a Pakistani Medical School". BMC Medical Education 10 No. 2(2010): 1-8.

${ }^{19}$ Maureen Johnson, "Community college students " perception of stress". Journal of Biology of Exercise, 5 No. 1(2009):15- 28.

${ }^{20}$ Jerusha Conner, Denise Pope, \& Mollie Galloway, "Success with less stress. Health and Learning 67 No. 4(2010): 54-58.

${ }^{21}$ A. O. Busari, "Stress inoculation techniques in fostering adjustment to academic stress among undergraduate students". British Journal of Humanities and Social Sciences 2 No.1(2011): 229 - 243 


\section{Correlation among Religious Orientation, Mental Health and Academic Performance at Higher Educational Level}

1. To trace out the factors responsible for performance in university scholars.

2. To identify the relationship in religious orientation and mental health among university scholars.

3. To study the relationship in religious orientation and academic achievement in university scholars.

4. To search the correlation between mental health and academic score of university scholars.

5. To investigate the difference among religious orientation, mental health and academic performance with respect to demographic variables among university students.

\section{Hypotheses of the Study}

Following are the hypotheses:

Ho1: There is no significant relationship among religious orientation, mental health and academic performance in university scholars.

Ho2: There is no substantial difference among religious orientation, mental health and academic performance with respect to demographic variables among university students.

Ho3: There is no significant impact of mental health and religious orientation on academic performance in university scholars.

\section{Research Design}

It was a descriptive study. Survey method was used for collection of the data from the respondents.

\section{Population and Sample}

All the BS level students enrolled in the university of education were the population of the study. Among 3000 enrolled scholars in university of Education campus Faisalabad, about 10\% sample (300 scholars) selected randomly. The representation of scholars was enabled by selecting them 


\section{Correlation among Religious Orientation, Mental Health and Academic Performance at Higher Educational Level}

from basic sciences and social sciences. One hundred and twenty-six scholars were males and one hundred and seventy-four were females.

\section{Instrumentation}

A self-developed questionnaire named, Religious Orientation and Mental Health Survey [ROMHS] was used. The religious orientation's scale was adapted from the study of.$^{22}$ Among eighteen items on religious orientation, 12 items were selected. Six items were developed for mental health of students. The achievement score was taken from previous semester result. The experts in the field of education has validated the questionnaire and it was pilot test on forty scholars out of sample. The Cronbach Alpha values of intrinsic religious orientation .861, extrinsic religious orientation .845 , and mental health .863 .

\section{Data Analysis}

Data were analyzed using SPSS 24. The demographic variables were identified using descriptive statistics. The inferential statistics was analyzed using t-test, Pearson $\mathrm{r}$ and regression.

Ho1: No apparent correlation among religious orientation, mental health and academic performance in university scholars.

\section{Table 1}

Correlation among Religious Orientation, Mental Health and Academic Performance of Students

22 Claudia Da Silva Almeida, "Religious Orientation and Pressure in Undergraduate Engineering Students" Unpublished Masters' Dissertation, Faculty of Humanities, University of the Witwatersrand, Johannesburg. 2006. 
relationship among religious orientation, mental health and academic performance among university students was rejected.

Ho2: No substantial difference among religious orientation, mental health and academic performance with respect to demographic variables in university scholars.

Table 2

Difference among Religious Orientation, Mental Health and Academic Performance

\begin{tabular}{llccccc}
\hline Indicators & Gender & $\mathbf{N}$ & $\mathbf{M}$ & $\mathbf{s d}$ & $\mathbf{t}$ & $\mathbf{P}$ \\
\hline Intrinsic RO & Male & 126 & 3.61 & .61 & 1.177 & .240 \\
& Female & 174 & 3.52 & .68 & & \\
Extrinsic RO & Male & 126 & 3.72 & .65 & 2.372 & $.018^{*}$ \\
& Female & 174 & 3.53 & .68 & & \\
Mental & Male & 126 & 3.80 & .64 & 2.333 & $.020^{*}$ \\
Health & Female & 174 & 3.60 & .76 & & \\
Religious & Male & 126 & 3.66 & .53 & 2.119 & $.035^{*}$ \\
Orientation & Female & 174 & 3.52 & .57 & & \\
\hline
\end{tabular}

$* \mathrm{p}<0.05$

In table 2, t-test showed an apparent difference in students' gender with religious orientation. The mean on extrinsic religious orientation of male scholars $(\mathrm{M}=3.72, \mathrm{SD}=.65)$ and females $(\mathrm{M}=3.53, \mathrm{SD}=.68, \mathrm{t}(298)=$ 2.372, $\mathrm{p}<0.05)$. Male scholars had higher extrinsic religious orientations than female scholars. The mental health of male scholars was found to higher than females. In the same way, the performance of male scholars was also higher than female students.

On the other hand, the overall mean achievement score on intrinsic religious orientation of male scholars $(\mathrm{M}=3.61, \mathrm{SD}=.61)$ and female scholars $(\mathrm{M}=3.52, \mathrm{SD}=.68, \mathrm{t}(298)=1.177, \mathrm{p}>0.05)$. Both categories of 
The Scholar Islamic Academic Research Journal

Vol. 5, No. 2 || July -December 2019 || P. 40-54

https://doi.org/10.29370/siarj/issue9ar9

scholars had same intrinsic religious orientation. So the null hypothesis that there is no significant difference among religious orientation, mental health and academic performance with respect to demographic variables among university students was partially rejected.

Ho3: There is no statistical significant effect of religious orientation and mental health on academic performance of higher educational students?

Table 3

Standardized Regression " $\beta$ ”, Simple Correlation “ $r$ ", and Multiple Correlation " $R$ ” (Academic Performance)

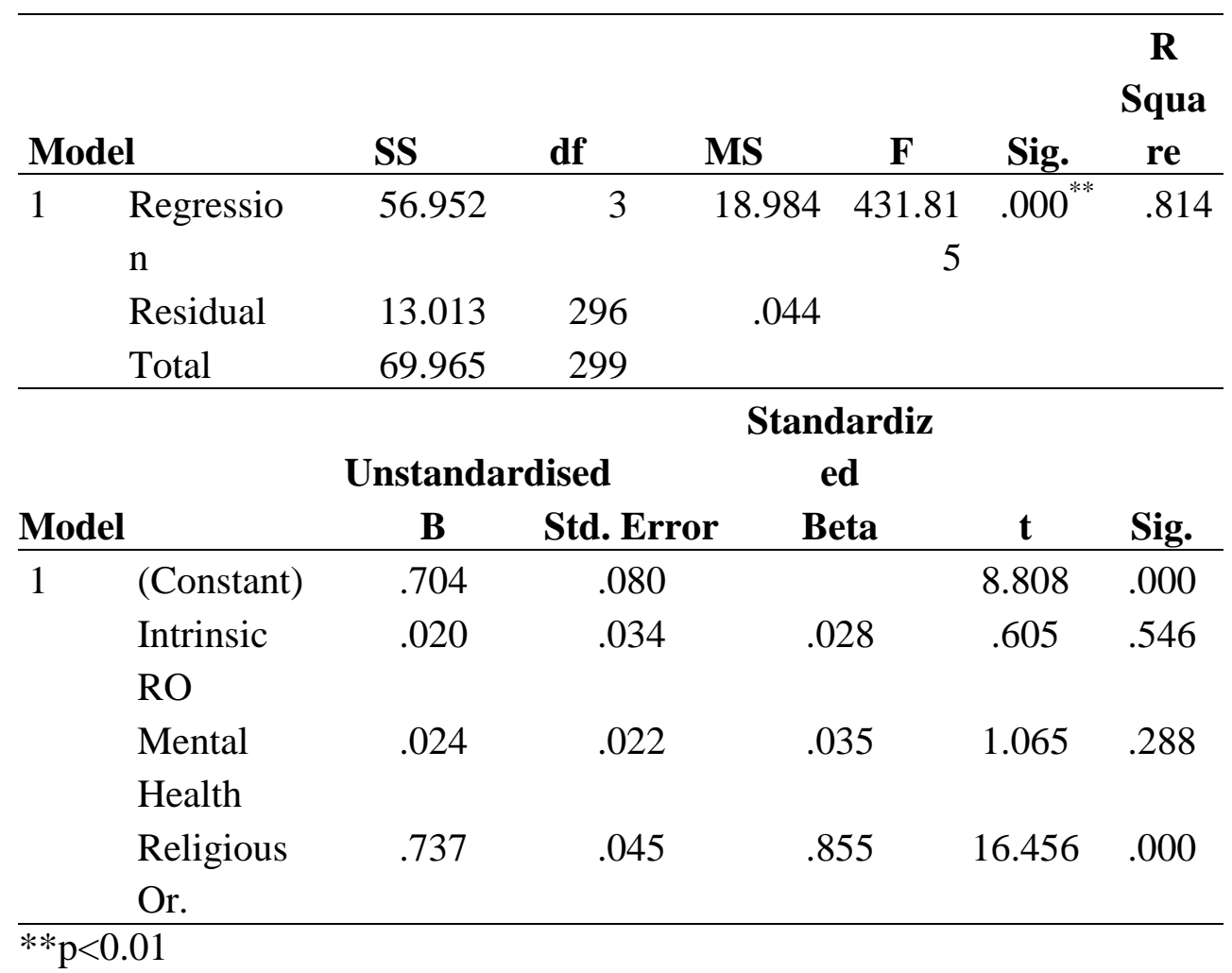

In table 3, linear regression (multiple) was used for the prediction of performance for religious orientation and mental health. It was significant as $(\mathrm{F}(3,296)=431.815, p<.000)$, with an $R^{2}$ of .814 . So, it was revealed 
The Scholar Islamic Academic Research Journal

Vol. 5, No. 2 || July -December 2019 || P. 40-54

https://doi.org/10.29370/siarj/issue9ar9

that about $81 \%$ of academic achievement score of university students was influenced by religious orientation and mental health.

\section{Findings and Conclusions}

A strong positive relationship exists among extrinsic, intrinsic and overall religious orientations. The study of ${ }^{23}$ showed that religious beliefs have both positive and negative effect on mental health with respect to personal religious concerns and consequences.

Male students were found to have greater extrinsic religious orientation, better mental health than that of female students. On the other hand, the overall mean achievement score on intrinsic religious orientation. Both genders have same academic performance. The study supported the findings of ${ }^{24}$ that significant correlation between metal well-being and religious beliefs of students.

The linear regression (multiple) showed that about $81 \%$ of academic achievement score of university students was influenced by mental health and religious orientation. Many studies have explored religious remedies and techniques to manage stressful measures and manage mental and physical health of students. ${ }^{25}$ Feeling of religious commitment is an effective way parents may cope with shocking news and keep the blood

${ }^{23}$ Alireza Jafari, "Relationship between religious orientation (InternalExternal) with methods of overcoming stress in students of Islamic Azad University of Abhar". Psychology Research 1 No. 4(2011): 239-243.

${ }^{24}$ Christopher G. Ellison, "Religious involvement and subjective wellbeing”. Journal of Health and Social Behavior 32 No. 1(1991): 80-99.

25 Moos, Rudolf H. \& Schaefer, Jeanne A, "Coping resources and processes: Current concepts and measures”. In: Goldberger L, Breznitz S, editors. Handbook of stress: Theoretical and clinical aspects. 2. (1993) New York: Free Press; pp. 234-257. 
circulation normal in the body. ${ }^{26}$ Psychologists refer religious orientation as a person's practices or lives about religious beliefs. The adjustment seemed to better anticipate by religious handling of common religious alignment. ${ }^{27}$

The intrinsic orientation is positively linked with better mental health and determination to cope with guilt and worries. Intrinsic religiosity anticipated low level of depression. ${ }^{28}{ }^{29}$ investigated a significant difference between the external and internal religious orientation in the emotion based coping methods like self-control, confrontation, avoidance and escaping.

The complex academic environment has great medical problems for pupils' lives and restricted the gains expected from university studies. ${ }^{30}$ It needed proper coping strategies of stress management in university for

${ }^{26}$ Crystal L. Park. \& Lawrence H. Cohen, "Religious and nonreligious coping with the death of friend". Journal of Cognitive Therapy and Research 17 No. 6(1993): 561-577.

${ }^{27}$ Christian Zwingmann, \& Sebastian Murken, "Coping with an uncertain future: Religiosity and millenarianism". Archives for Religions Psychology 23 (2000): 11-28.

${ }^{28}$ Sam G. McFarland \& James C. Warren, Jr., "Religious orientations and selective exposure among fundamentalist Christians". Journal for the Scientific Study of Religion, 31 No. 2(1992): 169-174.

${ }^{29}$ Alireza Jafari, "Relationship between religious orientation (InternalExternal) with methods of overcoming stress in students of Islamic Azad University of Abhar". Psychology Research 1 No. 4(2011): 239-243.

${ }^{30}$ Karen Danna, \& Ricky W. Griffin, "Health and well-being in the workplace: A review and synthesis of the literature". Journal of Management 25 No. 3(1999): 357-384. 
The Scholar Islamic Academic Research Journal

Vol. 5, No. 2 || July -December 2019 || P. 40-54

https://doi.org/10.29370/siarj/issue9ar9

effective academic progress. Students in universities have diverse expectations, values and goals needed to fulfill. ${ }^{31}$

In literature, many academic factors that are associated with academic performance are identified like time management, economic burdens, teachers' students' interaction, social activities, academic adjustment, campus life, group work stress, and lack of support from peers. ${ }^{32}$

In addition, admission criteria, high student-teacher ratio, overcrowded class rooms, absence of teacher-student communication, corporeal punishment, excessive school-work, teaching methods, and low emphasis on quality rather than quantity ${ }^{33}$, expectations from teachers and parents. ${ }^{34}$ The academic workload, class bunking, exams, overburdened syllabus ${ }^{35}$, lack of modern technology ${ }^{36}$, unable to use $\operatorname{ICT}^{37}$, low educational

31 Suhail Bhat, "Religious orientation and academic stress among university students". International Journal of Behavioral Research \& Psychology 3 No. 3(2015): 85-89.

32 Scott, E. Wilks, "Resilience amid academic stress: The moderating impact of social support among social work students". Advances in Social Work 9 No. 2 (2008): 106-125.

${ }^{33}$ Rudolph KD. \& Hammen C, "Age and gender as determinants of stress exposure, generation, and reactions in youngsters: A transactional perspective”. Child Development 70 No. 3(1999): 660-677.

${ }^{34}$ Rebecca P. Ang \& Vivien S. Huan, "Relationship between academic stress and suicidal ideation: Testing for depression as a mediator using multiple regression". Child Psychiatry and Human Development 37 No. 2(2006): 133-143.

${ }^{35}$ Mohsin Shah, Shahid Hasan, Samina Malik, \& Chandrashekhar T Sreeramareddy, Perceived Stress, Sources and Severity of Stress among medical undergraduates in a Pakistani Medical School". BMC Medical Education 10 No. 2(2010): 1-8.

${ }^{36}$ Joseph E. Agolla, \& Henry Ongori, "An assessment of academic stress among undergraduate students: The case of University of Botswana". Educational Research and Review 4 No. 2(2009): 63-70. 
The Scholar Islamic Academic Research Journal

Vol. 5, No. 2 || July -December 2019 || P. 40-54

https://doi.org/10.29370/siarj/issue9ar9

performance ${ }^{38}$, students' strength in classes and absence of academic assignments $^{39}$, unemployment feelings for upcoming ${ }^{40}$, and requirements. alleviation.

\section{(C) (1)(}

Attribution-NonCommercial-ShareAlike 4.0 International (CC BY-NC-SA 4.0)

${ }^{37}$ Mohsin Shah, Shahid Hasan, Samina Malik, \& Chandrashekhar T Sreeramareddy, Perceived Stress, Sources and Severity of Stress among medical undergraduates in a Pakistani Medical School". BMC Medical Education 10 No. 2(2010): 1-8.

${ }^{38}$ Maureen Johnson, "Community college students ' perception of stress". Journal of Biology of Exercise, 5 No. 1(2009):15- 28.

39 Jerusha Conner, Denise Pope, \& Mollie Galloway, "Success with less stress. Health and Learning 67 No. 4(2010): 54-58.

${ }^{40}$ Mohsin Shah, Shahid Hasan, Samina Malik, \& Chandrashekhar T Sreeramareddy, Perceived Stress, Sources and Severity of Stress among medical undergraduates in a Pakistani Medical School". BMC Medical Education 10 No. 2(2010): 1-8. 